\title{
Orphan Nuclear Bodies
}

\author{
Maria Carmo-Fonseca ${ }^{1}$, Maria T. Berciano ${ }^{2}$, and Miguel Lafarga ${ }^{2}$ \\ ${ }^{1}$ Instituto de Medicina Molecular, Faculdade de Medicina, Universidade de Lisboa, 1649-028 Lisboa, Portugal \\ ${ }^{2}$ Department of Anatomy and Cell Biology, and "Centro de Investigacion Biomedica en Red sobre Enfermedades \\ Neurodegenerativas (CIBERNED)", University of Cantabria, Santander 39011, Spain \\ Correspondence: carmo.fonseca@fm.ul.pt
}

Orphan nuclear bodies are defined as nonchromatin nuclear compartments that have been less well studied compared with other well-characterized structures in the nucleus. Nuclear bodies have traditionally been thought of as uniform distinct entities depending on the protein "markers" they contain. However, it is becoming increasingly apparent that nuclear bodies enriched in different sets of transcriptional regulators share a link to the ubiquitin-proteasome and SUMO-conjugation pathways. An emerging concept is that some orphan nuclear bodies might act as sites of protein modification by SUMO and/or proteasomal degradation of ubiquitin-tagged proteins. By defining a specialized environment for protein modification and degradation, orphan nuclear bodies may increase the capacity of cells to survive under varying environmental conditions.

\begin{abstract}
$A$ nuclear body is a region within the nucleus Athat is morphologically distinct from its surroundings when observed by transmission electron microscopy (reviewed in Spector 2006). This excludes structures that are only detected upon overexpression of tagged nuclear proteins and most likely result from nonphysiological aggregation of excess protein.

On the basis of their structure observed at the electron microscopic level, nuclear bodies have been classified as either simple or complex (Bouteille et al. 1974). The simple nuclear bodies are small $(0.2-0.5 \mu \mathrm{m})$, round, compact and finely fibrillar, whereas the complex nuclear bodies are larger $(0.2-1.2 \mu \mathrm{m})$, heterogeneous in shape and texture, and enveloped by a peripheral capsule, which gives them a doughnut-shaped appearance. Orphan nuclear
\end{abstract}

bodies are primarily proteinaceous structures enriched in either transcriptional regulators or RNA-binding proteins (Table 1). Although it was initially thought that these structures might act as specialized compartments for gene expression, most genes and RNA species targeted by the protein factors enriched in nuclear bodies show a widespread distribution throughout the nucleoplasm. Moreover, nuclear bodies contain only a fraction of the total pool of transcriptional regulators and RNA-binding proteins in the nucleus, and many of these factors are in constant flux in and out of the bodies.

A breakthrough in this field was the recent discovery that transcription factors enriched in nuclear bodies are modified by SUMO and/or ubiquitin, and that SUMO-conjugation plays an important role in nuclear body assembly

Editors: Tom Misteli and David Spector

Additional Perspectives on The Nucleus available at www.cshperspectives.org

Copyright (C) 2010 Cold Spring Harbor Laboratory Press; all rights reserved; doi: 10.1101/cshperspect.a000703

Cite this article as Cold Spring Harb Perspect Biol 2010;2:a000703 
M. Carmo-Fonseca et al.

Table 1. Orphan nuclear bodies

\begin{tabular}{|c|c|c|}
\hline Nuclear body & Description & Reference \\
\hline Clastosome & $\begin{array}{l}\text { Concentrates the proteasomal } 20 S \text { and } 19 S \\
\text { complexes, and ubiquitin conjugates. Detected } \\
\text { predominantly when the activity of the } \\
\text { proteasome is stimulated, disassembles upon } \\
\text { proteasomal inhibition. The number per cell } \\
\text { ranges between } 0 \text { and } 3 \text {, and the diameter is } \\
0.2-1.2 \mu \mathrm{m} \text {. }\end{array}$ & Lafarga et al. 2002 \\
\hline Cleavage body & $\begin{array}{l}\text { Enriched in cleavage factors CstF } 64 \mathrm{kDa} \text { and } \\
\text { CPSF } 100 \mathrm{kDa} \text {, and DEAD box protein DDX1. } \\
\text { Detected predominantly during } \mathrm{S} \text { phase, is not } \\
\text { affected by transcription inhibition. The } \\
\text { number per cell ranges between } 1 \text { and } 4 \text {, and } \\
\text { the diameter is } 0.2-1.0 \mu \mathrm{m} \text {. }\end{array}$ & $\begin{array}{l}\text { Schul et al. 1996; Bléoo et al. } \\
\text { 2001; Li et al. } 2006\end{array}$ \\
\hline OPT domain & $\begin{array}{l}\text { Enriched in transcription factors Oct1 and PTF. } \\
\text { Partial colocalization with transcription sites. } \\
\text { Detected predominantly during late G1 phase, } \\
\text { disassembles upon transcription inhibition. } \\
\text { The number per cell ranges between } 1 \text { and } 3 \text {, } \\
\text { and the diameter is } 1.0-1.5 \mu \mathrm{m} \text {. }\end{array}$ & Pombo et al. 1998 \\
\hline Polycomb body & $\begin{array}{l}\text { Enriched in PcG proteins in Drosophila embryos } \\
\text { and human cells. Concentrates human RING1, } \\
\text { BMI1, HPC, and some associate with } \\
\text { pericentromeric heterochromatin. The } \\
\text { number per cell ranges between } 12 \text { and 16, and } \\
\text { the diameter is } 0.3-1.0 \mu \mathrm{m} \text {. }\end{array}$ & $\begin{array}{l}\text { Buchenau et al. 1998; Saurin } \\
\text { et al. } 1998\end{array}$ \\
\hline Sam68 body & $\begin{array}{l}\text { Concentrates Sam68 and Sam68-like proteins } \\
\text { SLM-1 and SLM-2. Disassembles upon } \\
\text { transcription inhibition. Most likely enriched } \\
\text { in RNA. The number per cell ranges between } 2 \\
\text { and 5, and the diameter is } 0.6-1.0 \mu \mathrm{m} \text {. }\end{array}$ & Chen et al. 1999 \\
\hline SUMO body & $\begin{array}{l}\text { Enriched in SUMO-1 and SUMO- conjugating } \\
\text { enzyme Ubc9. Concentrates transcription } \\
\text { factors pCREB, CBP, c-Jun. The number per } \\
\text { cell ranges between } 1 \text { and } 3 \text {, and the diameter } \\
\text { is } 1-3 \mu \mathrm{m} \text {. }\end{array}$ & Navascués et al. 2007 \\
\hline
\end{tabular}

(reviewed in Heun 2007). It is therefore possible that some nuclear bodies act as protein modification and degradation centers.

\section{THE CLASTOSOME: A NUCLEAR BODY LINKED TO THE UBIQUITIN-PROTEASOME SYSTEM}

Proteins in cells and organisms exist in a dynamic state with individual half-lives ranging from minutes to years. This implies that protein degradation must be highly selective and tightly controlled (reviewed in Ravid and Hochstrasser 2008). Eukaryotic cells have two major mechanisms for protein degradation: lysosomes and proteasomes. Although exogenous particles and endogenous cellular organelles are targeted for digestion in lysosomes, the majority of intracellular proteins are degraded by proteasomes (reviewed in Murata et al. 2009). Proteasomes degrade short-lived regulatory proteins and thereby control cellular processes such as signal transduction, cell cycle, and gene transcription. Proteasomes additionally clear misfolded and 
aggregated proteins from the cell and produce some of the peptides to be displayed at the cell surface as part of the adaptive immune response.

A fundamental question about intracellular proteolysis is how specific proteins are recognized by the proteolytic machinery. In eukaryotic cells, most substrate proteins are targeted to the proteasome by the covalent attachment of many copies of the small protein ubiquitin. Once a protein has been tagged by polyubiquitination, it is recognized by the proteasome, unfolded and then degraded (Fig. 1). However, ubiquitination can function independently of the proteasome and proteasomes can degrade some proteins without their prior modification by ubiquitin (Ravid and Hochstrasser 2008).

The proteasome is an approximately 2.5MDa (26S) protein machine composed of two subcomplexes: a $20 \mathrm{~S}$ barrel-shaped core that carries the catalytic activity, and a flanking regulatory 195 particle that recognizes and unfolds protein substrates (reviewed in Cheng 2009). The $20 \mathrm{~S}$ core particle consists of four stacked rings that form a cavity at the center of the particle where the peptidolytic active sites are sequestered. Substrates gain access to this cavity through narrow pores present at either axial end of the core particle. These pores are normally closed and require a mechanism of gate opening carried out by the $19 \mathrm{~S}$ regulatory particle. One regulatory particle may associate with either axial end of the core particle. The regulatory particle contains ATPases presumed to function in substrate unfolding, and ubiquitin chain receptors responsible for recognition of the substrate proteins (Fig. 1).

Proteasomes were first shown to localize to the nucleus by Franke and colleagues (Hugle

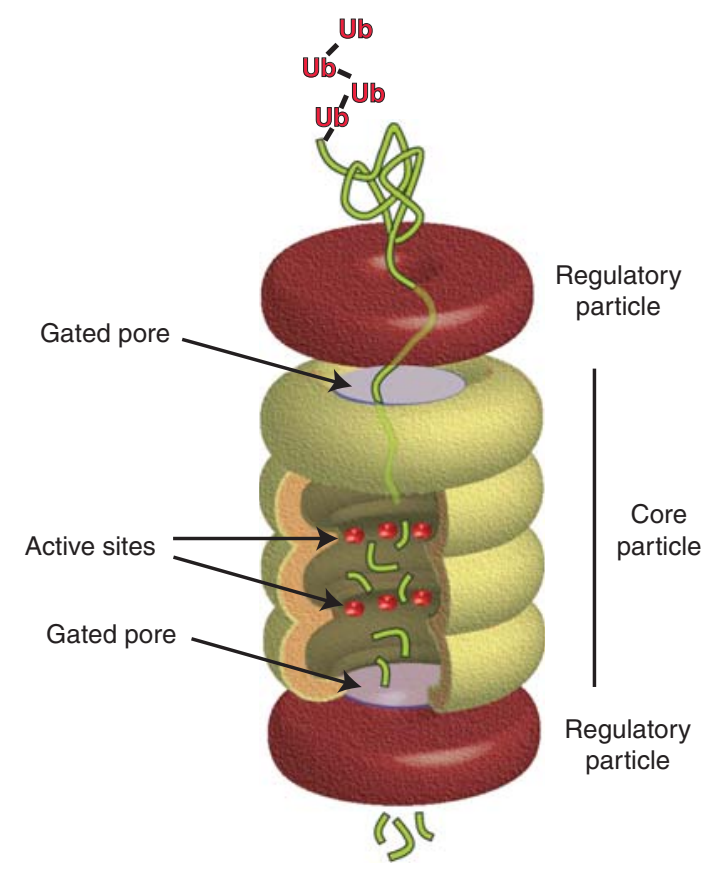

Figure 1. The 26S proteasome is composed of one core particle (20S) and one or two regulatory particles (19S). Proteins destined for degradation are initially attached to ubiquitin polymers. After this covalent modification, the substrate protein is able to bind (either directly or via adaptor proteins) to the $19 \mathrm{~S}$ regulatory complex. Then, the protein is unfolded by ATPases that encircle the entrance of the $20 \mathrm{~S}$ catalytic core, and the polyubiquitin chain is removed by proteasome-associated deubiquitylating enzymes. Finally, the unfolded protein is translocated into the central proteolytic chamber, where it is cleaved into short peptides. 


\section{Carmo-Fonseca et al.}

et al. 1983; Kleinschmidt et al. 1983). Subsequent studies confirmed that proteasomes, as well as components of the ubiquitin-proteasome system occur both in the nucleus and in the cytoplasm. Although some nuclear proteins, such as p53, are first exported from the nucleus and then degraded in the cytoplasm, several lines of evidence indicate that proteins can be ubiquitylated and degraded by the proteasome within the nucleus (Tao et al. 2005; Rockel et al. 2005).

Immunofluorescence studies using antibodies specific for the $20 \mathrm{~S}$ and $19 \mathrm{~S}$ proteasomal subcomplexes reveal that although proteasomes are most often diffusely distributed throughout the nucleoplasm, they occasionally concentrate in discrete structures (Fig. 2). By electron microscopy, these structures correspond to previously described complex, ring-shaped nuclear bodies (Bouteille et al. 1974). Doublelabeling experiments further show the presence of ubiquitin-conjugates, c-Jun and c-Fos, two short-lived transcription factors degraded by the ubiquitin-proteasome system, in the proteasome-containing nuclear bodies (Lafarga et al. 2002). Proteasome-containing nuclear bodies form in response to stimuli that activate proteasome-dependent proteolysis and disappear when proteasome function is inhibited. Taken together, these results suggest that proteasomecontaining nuclear bodies are sites of protein degradation, and the name clastosome (from the Greek klastos, broken and soma, body) was coined to refer to this nuclear domain (Lafarga et al. 2002).

Clastosomes are defined as nuclear bodies of irregular shape and size that contain both catalytic and regulatory subunits of the
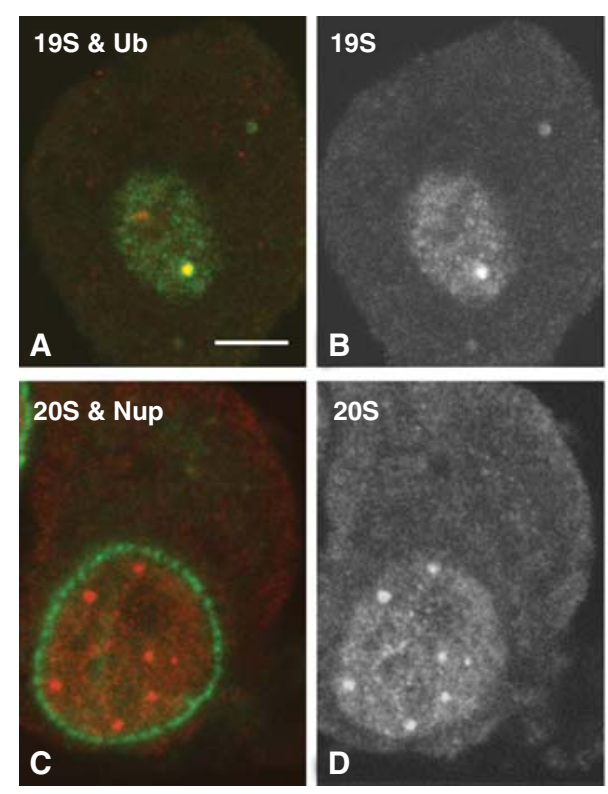

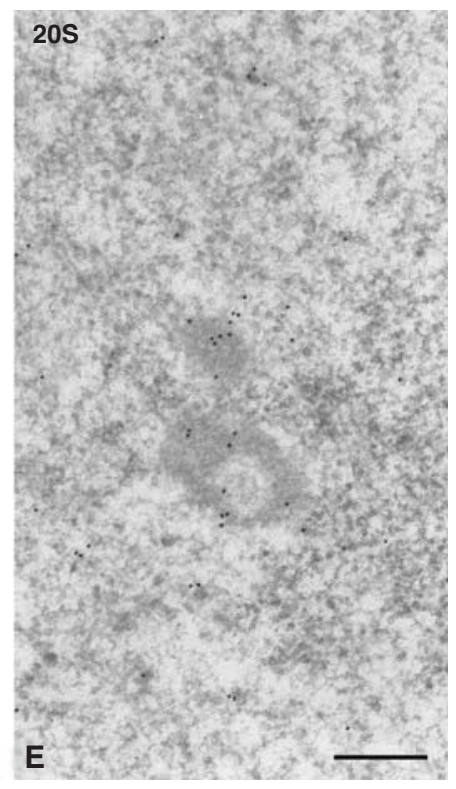

Figure 2. The clastosome is a nuclear body enriched in proteasomes. $(A, B)$ Colocalization of ubiquitin-conjugates $(A$, red staining) and 19 S proteasomal complexes ( $A$ and $B$, green staining) in a human neuron mechanically isolated from dorsal root ganglia obtained from an autopsy of a patient without any diagnosed neurological disorder. Bar, $5 \mu \mathrm{m}$. $(C, D)$ Several clastosomes are observed in the nucleus of a neurosecretory neuron isolated from rat hypothalamus after osmotic stress; double-immunofluorescence with antibodies specific to $20 \mathrm{~S}$ proteasomal complexes ( $C$ and $D$, red staining) and a nucleoporin $(C$, green staining). (E) Immunogold labeling with antibodies directed against the $20 \mathrm{~S}$ proteasome reveals a doughnutor ring-shaped nuclear body. Bar, $300 \mathrm{~nm}$. 
proteasome and ubiquitylated proteasome substrates. Clastosomes are normally absent or scarce in most cell types, indicating that these nuclear bodies are not essential for proteasome function. Most likely, protein substrates tagged for proteolysis are rapidly encountered, recognized and degraded by the diffusely distributed proteasomes in the nucleoplasm. Clastosomes become prominent when cells are exposed to stimuli that suddenly increase the levels of proteins targeted for degradation, for example, inducible expression of c-fos by serum, or stress. Clastosomes may therefore form as a result of an overload of protein substrates. Clastosomes assemble transiently and revert after the stimulus, consistent with the view that they accumulate substrates queuing up for proteolysis. Moreover, clastosomes are not detected in cells treated with specific proteasome inhibitors, arguing that clastosome assembly requires proteasomal activity. Clastosomes may also act by sequestering proteasomes, thereby controlling the availability of proteolytic machines for nuclear protein degradation.

Recent studies suggest that regulated protein degradation by the ubiquitin proteasome system is an important modulator of neuronal function (reviewed in Tai et al. 2008). In particular, the localization of proteasomes to synapses is controlled by synaptic stimulation, thus providing a mechanism for local protein turnover (Bingol and Schuman 2006). The observation that clastosomes are widespread in glial cells and many types of brain neurons (Ádori et al. 2006; Baltrons et al. 2008) raises the possibility that these nuclear bodies participate in distinctive features of protein turnover in the nervous system. The importance of proteolysis in neurons is further underlined by the presence in a wide spectrum of neurodegenerative diseases of pathological protein aggregates that lead to a severe impairment of the ubiquitin-proteasome system (Bennett et al. 2005). Although the presence of ubiquitin and proteasomes in inclusion bodies formed by disease-associated protein aggregates suggests a link with dysfunction of the ubiquitin-proteasome system (Janer et al. 2006), the mechanism by which accumulation of protein aggregates in inclusion bodies contributes to disease remains unknown (see Orr 2010).

\section{THE PROTEASOME IS A COMPONENT OF BOTH CLASTOSOMES AND PML NUCLEAR BODIES}

The PML protein colocalizes with ubiquitin and the proteasome in nuclear bodies (Zhong et al. 2000; Lallemand-Breitenbach et al. 2001; Lafarga et al. 2002). Recent studies show that PML can be modified by SUMO and this triggers its polyubiquitylation and proteasomal degradation (Tatham et al. 2008; LallemandBreitenbach et al. 2008). According to the model proposed by De Thé and colleagues (Lallemand-Breitenbach et al. 2001), after PML protein modification, proteasomes are recruited to primary PML bodies giving rise to mature PML nuclear bodies, which have a characteristic shell- or ring-like morphology by electron microscopy and are therefore indistinguishable from clastosomes. An alternative view is that modified PML protein is recruited to clastosomes (Fig. 3). As clastosomes form independently of PML protein (Lafarga et al. 2002), we favor the later model. Indeed, clastosomes can be seen in the nucleus containing distinct proteasome substrates, suggesting diversity among this type of nuclear bodies (Fig. 3). Clearly, it is crucial to determine what nucleates de novo assembly of a clastosome: Is it the proteasome, the protein substrate or a complex of proteasomes with associated substrates? Moreover, it is becoming increasingly apparent that the cell's population of proteasomes may actually represent a diverse group of functionally distinct members (Hanna et al. 2007; Hanna and Finley 2007). An exciting speculation is that clastosomes result from particular proteasome configurations that display novel and unique properties, distinct from the "canonical" forms present throughout the nucleoplasm.

\section{THE POLYCOMB BODY: A TRANSCRIPTIONAL REPRESSOR DOMAIN?}

Polycomb group (PcG) proteins are well-conserved, essential regulatory factors that bind 
M. Carmo-Fonseca et al.
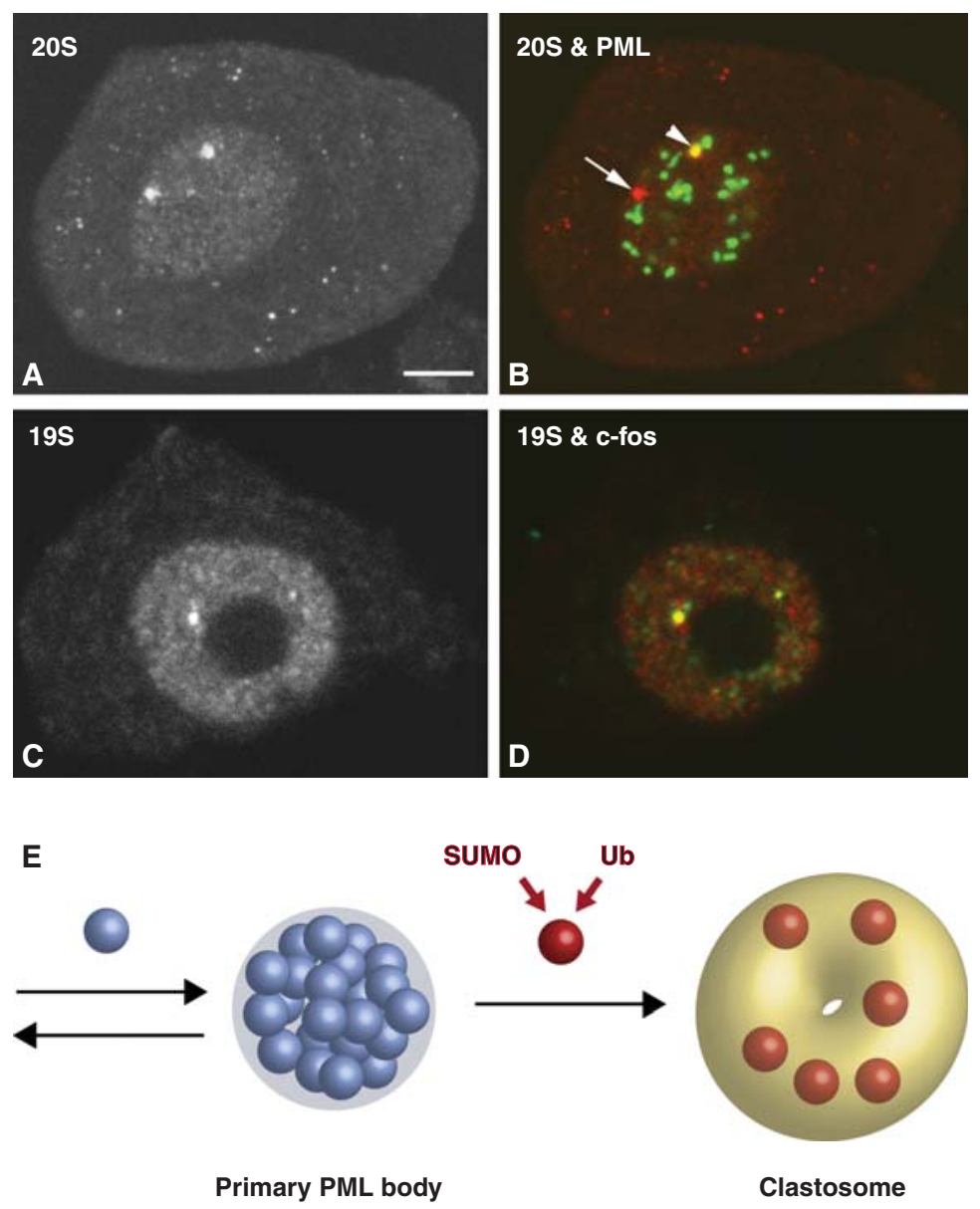

Figure 3. Clastosomes concentrate protein substrates for proteasomal degradation. $(A, B)$ The panels depict a human neuron mechanically isolated from dorsal root ganglia obtained from an autopsy of a patient without any diagnosed neurological disorder, double-labeled with anti-PML ( $B$, green staining) and anti-20S proteasomal complexes ( $A$ and $B$, red staining). Note that only one of the multiple PML bodies concentrates proteasomes (arrowhead) and that one body enriched in proteasomes does not contain PML (arrow). $(C, D)$ Colocalization of $19 S$ proteasomal complexes $(C$ and $D$, red staining) and c-Fos $(D$, green staining) in the nucleus of a neurosecretory neuron isolated from rat hypothalamus after osmotic stress. Bar, $5 \mu \mathrm{m}$. $(E)$ Hypothetical model for PML protein traffic through PML bodies and clastosomes. PML (blue spheres) distributes diffusely in the nucleoplasm and associates transiently with primary PML bodies. Upon modification by SUMO and ubiquitin, the modified PML proteins (red spheres) are recruited to clastosomes for degradation.

to specific DNA regions in target genes and repress their transcription. PcG proteins maintain the silenced state of developmental genes, including homeotic genes and genes involved in mammalian embryonic stem cell differentiation (Schuettengruber et al. 2007). PcG proteins were first described in Drosophila as factors responsible for maintaining the transcriptionally repressed state of Hox/homeotic genes throughout development. A growing number of vertebrate genes related to the Drosophila PcG proteins have recently been identified. PcG proteins exist in at least two distinct complexes termed Polycomb repressive complex 1 (PRC1) and Polycomb repressive complex 2 (PRC2). Members of PRC1, including 
the HPH1/HPH2, Bmi1, HPC2 and RING1 gene products are diffusely distributed in the nucleus and in addition colocalize in both Drosophila and mammalian cells as large nuclear domains termed Polycomb or PcG bodies (Buchenau et al. 1998; Saurin et al. 1998). In Drosophila, several genes that are repressed by PcG proteins localize to Polycomb bodies, suggesting that these domains correspond to sites of gene silencing (Grimaud et al. 2006). However, the number of Polycomb bodies is orders of magnitude smaller than the number of genetic loci targeted by PcG proteins. This implies that either multiple gene targets are associated with each Polycomb body or that gene silencing by PcG proteins can occur outside Polycomb bodies. Although endogenous homeotic genes appear to cluster at PcG bodies by a mechanism that requires components of the RNA interference machinery (Grimaud et al. 2006), it remains unknown whether assembly of a Polycomb body is necessary for the functional association of PcG proteins with chromatin.

\section{POLYCOMB AND PML NUCLEAR BODIES: THE SUMO CONNECTION}

The small ubiquitin-like modifier (SUMO) is an ubiquitin-related protein that can be covalently conjugated to a variety of protein substrates, altering the properties of the modified proteins. SUMO conjugation is essential for cell and organism viability, from yeast to mammals (Nacerddine et al. 2005), and affects many biological processes, including cell cycle progression, maintenance of genome integrity, and transcription (reviewed in Hay 2005). SUMO substrates include protein components of both PML and Polycomb nuclear bodies and recent evidence implicates the SUMOylation pathway as an important player in the assembly of these domains (Heun 2007).

The PML protein and the PML body components HIPK2, Daxx, and Sp100 are modified by SUMO. Moreover, SUMO conjugation is necessary for formation of PML bodies and for recruitment of HIPK2, Daxx, and Sp100 into the bodies (reviewed in Hay 2005). SUMO- modified HIPK2 represses the activity of bound transcription factors by associating with Groucho corepressor and HDAC1, and SUMO modification of Sp100 enhances its interaction with heterochromatin protein 1 (HP1), a well known initiator of repressive domains in chromatin.

The mechanism of SUMO conjugation involves a cascade of events catalysed by an activating enzyme E1, a conjugating enzyme E2 (known as Ubc9), and a protein ligase E3 (Hay 2005). There are at least three types of SUMO E3 ligases in cells: the protein inhibitor of activated signal transducer and activator of transcription (PIAS) family, the nuclear pore complex protein RanBP2/Nup358, and the Polycomb group protein Pc2. One of the substrates of Pc2 is the carboxy-terminal binding protein (CtBP) transcriptional corepressor (Kagey et al. 2003). It has been proposed that Pc2 functions to recruit Ubc9 and $\mathrm{CtBP}$ to $\mathrm{PcG}$ bodies, where SUMO modification of CtBP occurs (Kagey et al. 2004). More recently, the zinc finger protein CTCF was also shown to be recruited to Polycomb bodies and to be modified by SUMO (MacPherson et al. 2009).

Intriguingly, only a small proportion of the total cellular pool of a given transcription factor is modified by SUMO. Yet, the entire population is functionally repressed. The following model was proposed to accommodate these observations: Upon conjugation to SUMO, a transcription factor is incorporated into a repression complex located in a nuclear body; even if SUMO is removed from the transcription factor at a later stage by specific proteases, the protein would still be retained in the repression complex (Hay 2005). Consistent with this view, PML and Polycomb nuclear bodies might result from the assembly of SUMO-dependent repression complexes. A variation of this hypothesis postulates that a SUMO-modified transcription factor recruits an enzyme capable of posttranslationally modifying chromatin. SUMO could then be removed from the transcription factor, whereas transcriptional repression would be maintained by the chromatin modification (Hay 2005). According to this alternative view, PML and Polycomb nuclear bodies could be sumoylation centers, from 
M. Carmo-Fonseca et al.

which SUMO-modified transcription factors would be released. Consistent with the model that nuclear bodies can act as sites for SUMOconjugation, the SUMO-conjugating enzyme Ubc9 is highly enriched in these structures (Navascués et al. 2007) (Fig. 4).

\section{SEVERAL TRANSCRIPTIONAL REGULATORS LOCALIZE TO NUCLEAR BODIES}

Many transcription factors associated with RNA polymerase II and III activity appear uniformly distributed throughout the nucleoplasm. In addition, some of these factors are found concentrated in larger nuclear domains, at least in some cell lines. A well characterized example is the so-called OPT domain, a region of approximately $1.3 \mu \mathrm{m}$ in diameter that concentrates transcription factors Octl and PTF
(Pombo et al. 1998; Grande et al. 1997). The OPT domain is dynamic during the cell cycle: It appears during G1 phase and disappears in $S$ phase. The OPT domain is also transcriptiondependent: the transcription inhibitor DRB inhibits its formation and hastens its disappearance (Pombo et al. 1998). Although it has been proposed that the OPT domain might play a role in clustering genes on different chromosomes to a region where the appropriate transcription factors are concentrated (Pombo et al. 1998), as yet there is no evidence to support this view. In particular, genes that contain PTF and Oct1-binding sites have not been observed to colocalize in the domain. Alternatively, the OPT domain may contain intermediary complexes of transcription factors that form independently of their binding to regulatory sequences in target genes. Consistent with this
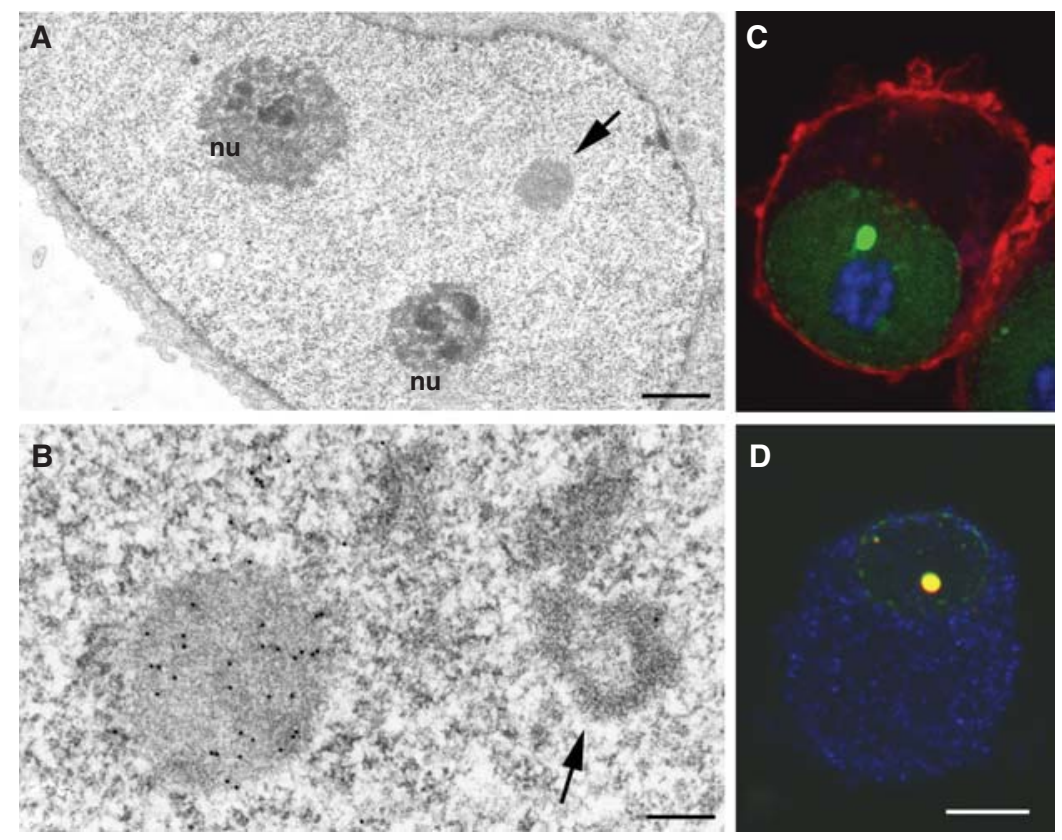

Figure 4. SUMO-1 localizes to nuclear bodies in neuron-like UR61 cells. (A) Electron microscopy reveals the presence of a round body (arrow) in the nucleus (nu, nucleolus). Bar, $1 \mu \mathrm{m}$. (B) Immunogold labeling of a nuclear body using antibodies specific for SUMO-1 (an arrow points to an adjacent doughnut-shaped structure that is most probably a clastosome). Bar, $300 \mathrm{~nm}$. (C) The distribution of SUMO-1 is detected in green by immunofluore-scence; the nucleolus is blue (immunofluorescence with antifibrillarin antibody) and the cell periphery is red (Rhodamine-Phalloidin Staining). (D) Co-localization of GFP-SUMO-1 (green) and SUMO E2 conjugating enzyme DsRed-Ubc9 (red) in nuclear bodies; the cytoplasm is stained blue (immunofluo-rescence with anti-SMN antibody). Bar, $5 \mu \mathrm{m}$. 
view, nuclear domains enriched in transcription factors could form as a result of protein modification, namely SUMOylation, as suggested for PML bodies and more recently, for a novel type of nuclear body that concentrates KRABzinc finger transcriptional regulators (Briers et al. 2009).

\section{RNA-BINDING PROTEINS IN NUCLEAR BODIES}

Members of three major classes of RNA-binding proteins localize to orphan nuclear bodies. These include Sam68 and the related SLM-1 and SLM-2 proteins of the signal transduction and activation of RNA (STAR) family, two subunits of the cleavage stimulation factor (CstF) and the cleavage and polyadenylation specificity factor (CPSF) components of the mRNA 3 -end processing machinery, and DDX1, a member of the DEAD box protein family of RNA helicases.

Sam68 belongs to the STAR family of proteins characterized by a KH (hnRNP K homology) domain embedded in a highly conserved region called GSG (GRP33/Sam68/GLD1) domain, which is required for homodimerization and sequence-specific RNA binding. Sam68 is a substrate for Src tyrosine kinases and is therefore considered a strong candidate to integrate signal transduction pathways and RNA metabolism, particularly alternative splicing (Paronetto et al. 2007). Although Sam68 can translocate to the cytoplasm and associate with specific RNAs in polysomes (Grange et al. 2009; Paronetto et al. 2009), the protein is predominantly detected in the nucleus (Fig. 5). Sam68 localizes diffusely in the nucleoplasm but additionally concentrates in a few prominent structures termed Sam68 nuclear bodies or SNBs (Chen et al. 1999). SNBs are dynamic structures that disassemble during mitosis and after treatment of cells with transcriptional inhibitors. Occasionally they appear adjacent to the nucleolus (Fig. 5) or to a Cajal body. Electron microscopic studies show that SNBs contain nucleic acids, presumably RNA, and targeting of Sam 68 to these structures involves the highly conserved GSG protein domain (Chen et al. 1999). Thus, SNBs might form as a result of
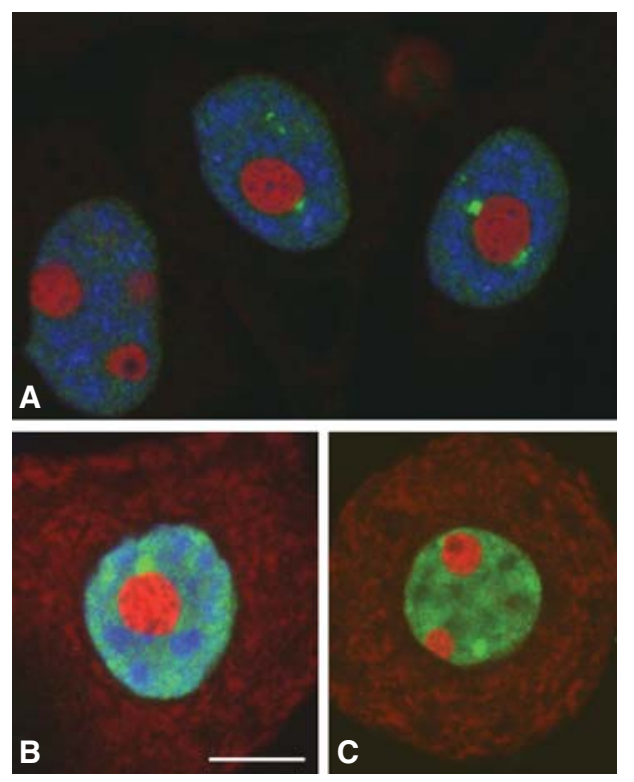

Figure 5. The RNA-binding protein Sam68 localizes to nuclear bodies in both Hela cells $(A)$ and rat neurons $(B, C)$. Sam 68 is detected in green by immunofluorescence labeling. Nucleoli and cytoplasm are detected in red (propidium iodide staining). RNA splicing speckles are detected in blue (immunofluorescence with an antibody directed against the 2, 2, 7trimethylguanosine cap structure of snRNAs). Bar, $10 \mu \mathrm{m}$.

Sam68 self-assembly and binding to specific RNAs in the nucleus. Although the identity of such potential scaffold RNAs remains to be determined, they are expected to be short-lived because SNBs disassemble within a few hours after transcription inhibition (Chen et al. 1999). Recently, Sam68 was reported to be modified by SUMO (Babic et al. 2006), and a pending question is whether SUMOylation is related to formation of SNBs.

CPSF and CstF are multiprotein complexes involved in formation of the $3^{\prime}$-ends of most mRNAs (reviewed in Danckwardt et al. 2008). The CPSF $100 \mathrm{kDa}$ subunit and the CstF 64 $\mathrm{kDa}$ subunits are diffusely distributed throughout the nucleoplasm and additionally concentrate in a few bright foci termed cleavage bodies (Schul et al. 1996). Cleavage bodies are primarily observed during $\mathrm{S}$ phase, apparently do not contain RNA, and are not affected 
M. Carmo-Fonseca et al.

by inhibitors of RNA transcription ( $\mathrm{Li}$ et al. 2006). Cleavage bodies often concentrate the DEAD box protein DDX1 (Bléoo et al. 2001) and are frequently found adjacent to Cajal bodies (Li 2006).

\section{CONCLUDING REMARKS}

Unlike the nucleolus, most types of orphan nuclear bodies are not detected in all cell types. It is therefore unlikely that these structures play an essential role in the nucleus. In general, orphan nuclear bodies are dynamic structures that assemble and disassemble at specific stages of the cell cycle or in response to changes in environmental conditions. A fundamental question is whether bodies form under these specific conditions as a result of aggregation of excessive protein that is not used, or contribute to increase the capacity of cells to survive under varying environmental stresses. Noteworthy, SUMOylation of the Caenorhabditis elegans PcG protein SOP-2 is required for both its localization to nuclear bodies and its physiological repression of Hox genes (Zhang et al. 2004). In further agreement with the view that nuclear bodies are functionally relevant, several lines of evidence implicate SUMOylation in assembly of PML nuclear bodies and maintenance of cell viability (Heun 2007).

Taken together, these results suggest that some nuclear bodies might represent sites of SUMO-conjugation and/or protein degradation by the ubiquitin-proteasome system, whereas others are more likely associated with transcription regulation and RNA metabolism. Further studies are needed to understand precisely what roles these different types of bodies play in the nucleus.

\section{ACKNOWLEDGMENTS}

We thank our colleagues João Ferreira and José Rino for stimulating discussions and help in some figures. Our laboratories are supported by grants from Fundação para a Ciência e Tecnologia, Portugal (PTDC/BIA-BCM/101575/ 2008), the European Commission (LSHG-CT2005-518238 and MRTN-CT-2006-035733),
"Dirección General de Investigacion" (BFU200800175, Spain) and CIBERNED (CB06/05/ 0037, Spain).

\section{REFERENCES}

Ádori C, Löw P, Moszkovkin G, Bagdy G, László L, Kovács GG. 2006. Subcellular distribution of components of the ubiquitin-proteasome system in non-diseased human and rat brain. J Histochem Cytochem 54: 263-267.

Babic I, Cherry E, Fujita DJ. 2006. SUMO modification of Sam68 enhances its ability to repress cyclin D1 expression and inhibits its ability to induce apoptosis. Oncogene 25: 4955-4964.

Baltrons MA, Pifarré P, Berciano MT, Lafarga M, García A. 2008. LPS-induced down-regulation of NO-sensitive guanylyl cyclase in astrocytes occurs by proteasomal degradation in clastosomes. Mol Cell Neurosci 37: 494-506.

Bennett EJ, Bence NF, Jayakumar R, Kopito RR. 2005. Global impairment of the ubiquitin-proteasome system by nuclear or cytoplasmic protein aggregates precedes inclusion body formation. Mol Cell 17: 351-365.

Bingol B, Schuman EM. 2006. Activity-dependent dynamics and sequestration of proteasomes in dentritic spines. Nature 441: 1144-1148.

Bléoo S, Sun X, Hendzel M, Rowe JM, Packer M, Godbout R. 2001. Association of human DEAD box protein DDX1 with a cleavage stimulation factor involved in $3^{\prime}$-end processing of pre-mRNA. Mol Biol Cell 12: 3046-3059.

Bouteille M, Laval M, Dupuy-Coin AM. 1974. Localization of nuclear functions as revealed by ultrastructural autoradiography and cytochemistry. In The cell nucleus, (ed. H. Busch), Vol. I, pp. 3-71. Academic Press, New York.

Briers S, Crawford C, Bickmore WA, Sutherland HG. 2009. KRAB zinc-finger proteins localize to novel KAP1containing foci that are adjacent to PML nuclear bodies. J Cell Sci 122: 937-946.

Buchenau P, Hodgson J, Strutt H, Arndt-Jovin DJ. 1998. The distribution of polycomb-group proteins during cell division and development in Drosophila embryos: impact on models for silencing. J Cell Biol 141: 469-481.

Chen T, Boisvert F-M, Bazett-Jones DP, Richard S. 1999. A role for the GSG domain in localizing Sam68 to novel nuclear structures in cancer cell lines. Mol Biol Cell 10: 3015-3033.

Cheng Y. 2009. Toward an atomic model of the $26 \mathrm{~S}$ proteasome. Curr Opin Struct Biol 19: 203-208.

Danckwardt S, Hentze MW, Kulozik AE. 2008. $3^{\prime}$ end mRNA processing: Molecular mechanisms and implications for health and disease. EMBO J 27: 482-498.

Grande MA, van der Kran I, de Jong L, van Driel R. 1997. Nuclear distribution of transcription factors in relation to sites of transcription and RNA polymerase II. J Cell Sci 110: 1781-1791.

Grimaud C, Bantignies F, Pal-Bhadra M, Ghana P, Bhadra U, Cavalli G. 2006. RNAi components are required for nuclear clustering of Polycomb group response elements. Cell 124: 957-971.

Grange J, Belly A, Dupas S, Trembleau A, Sadoul R., Goldberg Y. 2009. Specific interaction between San68 and 
neuronal mRNAs: Implication for the activity-dependent biosynthesis of elongation factor eEF1A. J Neurosci Res 87: 12-25.

Hanna J, Finley D. 2007. A proteassome for all occasions. FEBS Lett 581: 2854-2861.

Hanna J, Meides A, Zhang DP, Finley D. 2007. A ubiquitin stress response induces altered proteasome composition. Cell 129: 747-759.

Hay RT. 2005. SUMO: a history of modification. Mol Cell 18: $1-12$.

Heun P. 2007. SUMOrganization of the nucleus. Curr Opin Cell Biol 19: 350-355.

Hugle B, Kleinschmidt JA, Franke WW. 1983. The 22S cylinder particles of Xenopus laevis. II. Immunological characterization and localization of their proteins in tissues and cultured cells. Eur J Cell Biol 32: 157-163.

Janer A, Martin E, Muriel M-P, Latouche M, Fujigasaki H, Ruberg M, Brice A, Trottier Y, Sittler A. 2006. PML clastosomes prevent nuclear accumulation of mutant ataxin-7 and other polyglutamine proteins. J Cell Biol 174: 65-76.

Kagey MH, Melhuish TA, Wotton D. 2003. The polycomb protein Pc2 is a SUMO E3. Cell 113: 127-137.

Kagey MH, Melhuish TA, Powers SE, Wotton D. 2004. Multiple activities contribute to Pc2 E3 function. EMBO J 24: $108-119$.

Kleinschmidt JA, Hugle B, Grund C, Franke WW. 1983. The $22 \mathrm{~S}$ cylinder particles of Xenopus laevis. I. Biochemical and electron microscopic characterization. Eur J Cell Biol 32: 143-156.

Lafarga L, Berciano MT, Pena E, Mayo I, Castaño JG, Bohmann D, Rodrigues JP, Tavanez JP, Carmo-Fonseca M. 2002. Clastosome: a subtype of nuclear body enriched in 195 and 20 S proteasomes, ubiquitin, and protein substrates of proteasome. Mol Biol Cell 13: 2771-2782.

Lallemand-Breitenbach V, Zhu J, Puvion F, Koken M, Honoré N, Doubeikovsky A, Duprez E, Pandolfi PP, Puvion E, Freemenot P, et al. 2001. Role of promyelocytic leukemia (PML) sumolation in nuclear body formation, 11S proteasome recruitment, and As2O3-induced PML or PML/retinoic acid receptor $\alpha$ degradation. J Exp Med 193: $1361-1371$.

Lallemand-Breitenbach V, Jeanne M, Benhenda S, Nasr R, Lei M, Peres L, Zhou J, Zhu J, Raught B, de Thé H. 2008. Arsenic degrades PML or PML-RARalpha through a SUMO-triggered RNF4/ubiquitin-mediated pathway. Nat Cell Biol 10: 547-555.

Li L, Roy K, Katyal S, Sun X, Bléoo S, Godbout R. 2006. Dynamic nature of cleavage bodies and their spatial relationship to DDX1 bodies, Cajal bodies and Gems. Mol Biol Cell 17: 1126-1140.

MacPherson MJ, Beatty LG, Zhou W, Du M, Sadowski PD. 2009. The CTCF insulator protein is posttranslationally modified by SUMO. Mol Cell Biol 29: 714-725.

Murata S, Yashiroda H, Tanaka K. 2009. Molecular mechanisms of proteasome assembly. Nat Rev Mol Cell Biol 10: $104-115$.

Nacerddine K, Lehembre F, Bhaumik M, Artus J, CohenTannoudji M, Babinet C, Pandolfi PP, Dejean A. 2005. The SUMO pathway is essential for nuclear integrity and chromosome segregation in mice. Dev Cell 9: 769-779.
Navascués J, Bengoechea R, Tapia O, Vaqué JP, Lafarga M, Berciano MT. 2007. Characterization of a new SUMO-1 nuclear body (SNB) enriched in pCREB, CBP, c-Jun in neuron-like UR61 cells. Chromosoma 116: 441-451.

Orr HT. 2010. Nuclear ataxias. Cold Spring Harb Perspect Biol 2: a000786.

Paronetto MP, Achsel T, Massiello A, Chalfant CE, Sette C. 2007. The RNA-binding protein Sam 68 modulates the alternative splicing of Bcl-x. J Cell Biol 176: 929-939.

Paronetto MP, Messina V, Bianchi E, Barchi M, Vogel G, Moretti C, Palombi F, Stefanini M, Geremia R, Richard S, et al. 2009. Sam68 regulates translation of target mRNAs in male germ cells, necessary for mouse spermatogenesis. J Cell Biol 185: 235-249.

Pombo A, Cuello P, Schul W, Yoon J-B, Roeder RG, Cook PR, Murphy S. 1998. Regional and temporal specialization in the nucleus: a transcriptionally-active nuclear domain rich in PTF, Octl and PIKA antigens associates with specific chromosomes early in the cell cycle. EMBO J 17: $1768-1778$.

Ravid T, Hochstrasser M. 2008. Degradation signal diversity in the ubiquitin-proteasome system. Nat Rev Mol Cell Biol 9: 679-690.

Rockel TD, Stuhlmann D, von Mikecz A. 2005 Proteasomes degrade proteins in focal subdomains of the human cell nucleus. J Cell Sci 118: 5231-5242.

Saurin AJ, Shiels C, Williamson J, Satijn DP, Otte AP, Sheer D, Freemont PS. 1998. The human polycomb group complex associates with pericentromeric heterochromatin to form a novel nuclear domain. J Cell Biol 142: 887-898.

Schuettengruber B, Chourrout D, Vervoort M, Leblanc B, Cavalli G. 2007. Genome regulation by Polycomb and Trithorax proteins. Cell 128: 735-745.

Schul W, Groenhout B, Koberna K, Takagaki Y, Jenny A, Manders EMM, Raska I, van Driel R, de Jong L. 1996. The RNA $3^{\prime}$ cleavage factors CstF $64 \mathrm{kDa}$ and CPSF $100 \mathrm{kDa}$ are concentrated in nuclear domains closely associated with coiled bodies and newly synthesized RNA. EMBO J 15: 2883-2892.

Spector DL. 2006. SnapShot: cellular bodies. Cell 127: 1070-1070.e1.

Tai HC, Schuman EM. 2008. Ubiquitin, the proteasome and protein degradation in neuronal function and dysfunction. Nat Rev Neurosci 9: 826-838.

Tao LZ, Cheung AY, Nibau C, Wu HM. 2005. RAC GTPases in tobacco and Arabidopsis mediate auxin-induced formation of proteolytically active nuclear protein bodies that contain AUX/IAA proteins. Plant Cell 17: 2369-2383.

Tatham MH, Geoffroy MC, Shen L, Plechanovova A, Hattersley N, Jaffray EG, Palvimo JJ, Hay RT. 2008. RNF4 is a poly-SUMO-specific E3 ubiquitin ligase required for arsenic-induced PML degradation. Nat Cell Biol 10: $538-546$.

Zhang H, Smolen GA, Palmer R, Christoforu A, van den Heuvel S, Haber DA. 2004. SUMO modification is required for in vivo Hox gene regulation by the Caenorhabditis elegans Polycomb group protein SOP-2. Nat Genet 36: 507-511.

Zhong S, Salomoni P, Pandolfi PP. 2000. The transcriptional role of PML and the nuclear body. Nat Cell Biol 2: E85-E90. 


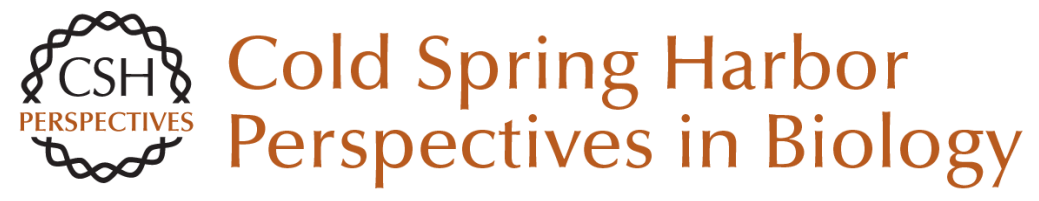

\section{Orphan Nuclear Bodies}

Maria Carmo-Fonseca, Maria T. Berciano and Miguel Lafarga

Cold Spring Harb Perspect Biol 2010; doi: 10.1101/cshperspect.a000703 originally published online July 7, 2010

\section{Subject Collection The Nucleus}

Nuclear Compartments: An Incomplete Primer to Nuclear Compartments, Bodies, and Genome Organization Relative to Nuclear Architecture Andrew S. Belmont

Uncovering the Principles of Genome Folding by 3D Chromatin Modeling

Asli Yildirim, Lorenzo Boninsegna, Yuxiang Zhan, et al.

3D or Not 3D: Shaping the Genome during Development Juliane Glaser and Stefan Mundlos

The Impact of Space and Time on the Functional Output of the Genome Marcelo Nollmann, Isma Bennabi, Markus Götz, et al.

Chromatin Mechanisms Driving Cancer

Berkley Gryder, Peter C. Scacheri, Thomas Ried, et al.

Liquid-Liquid Phase Separation in Chromatin Karsten Rippe

Mechanical Forces in Nuclear Organization Yekaterina A. Miroshnikova and Sara A. Wickström

Imaging Organization of RNA Processing within the Nucleus

Jeetayu Biswas, Weihan Li, Robert H. Singer, et al.
Mechanisms of Chromosome Folding and Nuclear Organization: Their Interplay and Open Questions Leonid Mirny and Job Dekker

Epigenetic Reprogramming in Early Animal Development

Zhenhai Du, Ke Zhang and Wei Xie

Essential Roles for RNA in Shaping Nuclear Organization

Sofia A. Quinodoz and Mitchell Guttman

The Molecular and Nuclear Dynamics of

$\mathrm{X}$-Chromosome Inactivation

François Dossin and Edith Heard

Structure, Maintenance, and Regulation of

Nuclear Pore Complexes: The Gatekeepers of the

Eukaryotic Genome Marcela Raices and Maximiliano A. D'Angelo

The Nuclear Lamina Xianrong Wong, Ashley J. Melendez-Perez and Karen L. Reddy

The Nuclear Pore Complex as a Transcription Regulator Michael Chas Sumner and Jason Brickner

Physical Nature of Chromatin in the Nucleus Kazuhiro Maeshima, Shiori lida and Sachiko Tamura

For additional articles in this collection, see http://cshperspectives.cshlp.org/cgi/collection/

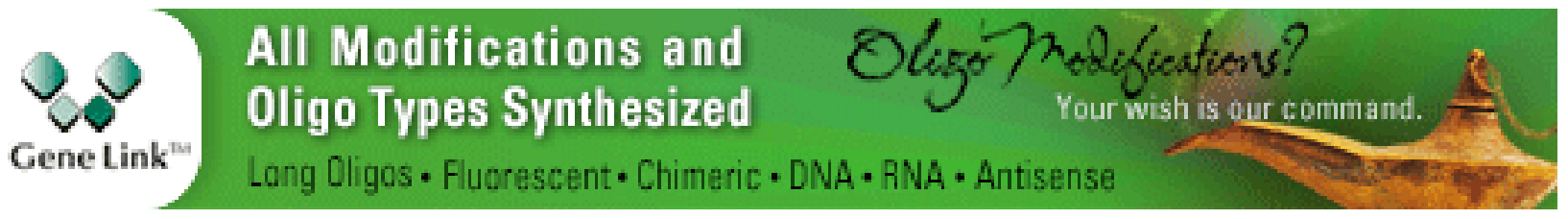


For additional articles in this collection, see http://cshperspectives.cshlp.org/cgi/collection/

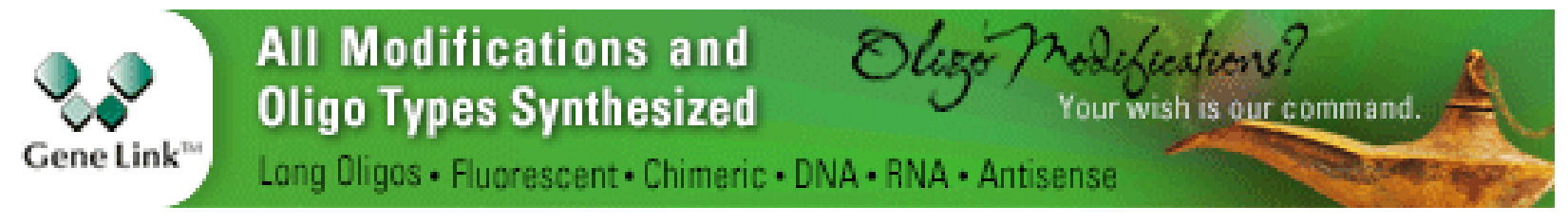

Copyright @ 2010 Cold Spring Harbor Laboratory Press; all rights reserved 